\title{
Prevalence of Ectoparasitic Infection of Rodents Captured near Student's Hostels: Zoonotic Implications
}

\author{
Tijjani Mustapha ${ }^{1,2^{*}}$, Ngah Zasmy Unyah ${ }^{1}$, Roslaini Abd Majid ${ }^{1}$, \\ Sharif Alhassan Abdullahi ${ }^{1,3}$ and Nasiru Mohammed Wana ${ }^{1,4}$ \\ ${ }^{1}$ Department of Medical Microbiology and Parasitology, Faculty of Medicine and Health Sciences, \\ University Putra Malaysia, 43400 UPM, Serdang, Malaysia. \\ ${ }^{2}$ Department of Biological Sciences, Faculty of Science, Yobe State University, Damaturu, Nigeria. \\ ${ }^{3}$ College of Health Sciences, Bayero University Kano, Nigeria. \\ ${ }^{4}$ Department of Biological Sciences, Faculty of Sciences, Abubakar Tafawa Balewa University, \\ Bauchi, Nigeria.
}

Authors' contributions

This work was carried out in collaboration among all authors. Author TM designed the study, performed the statistical analysis, wrote the protocol and wrote the first draft of the manuscript. Authors RAM, SAA and NMW managed the analyses of the study. Author NZU managed the literature searches. All authors read and approved the final manuscript.

Article Information

DOI: $10.9734 / A R R B / 2019 / v 32 i 130074$ Editor(s):

(1) Dr. Ibrahim Farah, Professor, Jackson State University, Mississippi, USA. (2) Dr. George Perry, Dean and Professor of Biology, University of Texas at San Antonio, USA. Reviewers:

(1) Adaobi Patricia Ugbomeh, Rivers State University, Nigeria. (2) Nayana Gunathilaka, University of Kelaniya, Sri Lanka Complete Peer review History: http://www.sdiarticle3.com/review-history/49523

Original Research Article

Received 29 March 2019

Accepted 11 June 2019

Published 18 June 2019

\section{ABSTRACT}

Background and Aims: Rodents constitute more than $42 \%$ of the known mammalian species, with 1700 species which belongs to three different families, include Muridae, Microtidae, and Sigmodontidae. Rodents species such as $R$. $r$. diardii and $R$. norvegicus play an important role as hosts for ectoparasites and reservoirs for various types of viruses, bacteria, rickettsia, protozoa, and helminths which are responsible for causing zoonotic diseases to humans and other vertebrate animals. The aim of this work is to identify the species of mites, ticks, and fleas causing 
diseases to humans and determined the prevalence of infestation in relation to gender, age, and habitat of the rodents.

Place and Duration of the Study: Department of Medical Microbiology and Parasitology, Faculty of Medicine and Health Sciences, University Malaysia, Between September 2018 and March 2019. Methodology: Wild rats were captured using live traps from garbage areas, and places near the cafeteria in the student's residential colleges at University Putra Malaysia. The rats were humanely euthanised and identified. They were classified as adult or juveniles. Their sex was also determined. Ectoparasites were collected by combing the fur the rodents on to a white plan sheet paper. The ectoparasites collected were washed and mounted with Hoyer's media on a glass slide. Parasites were identified using a key morphological feature.

Results: A total of 89 wild rats were trapped and examined for ectoparasites. Eight different species of ectoparasites that comprised of L. echidnanus, L. nuttalli, O. bacoti, I. granulatus, Heamaphysalis sp., $P$. spinoluso, $H$. pacifica, $X$. cheopis) were identified from the rodents examined. About $55 \%$ of the rodents trapped were positive for at least one species of ectoparasite parasites, and about $45.8 \%$ of the male rats and $30.8 \%$ of female were positive for ectoparasites. Meanwhile, in the adult, $42.9 \%$ are positive for at least one species of ectoparasites, whereas $32.2 \%$ of the juvenile rodent was also found positive for at least one species of ectoparasites.

Conclusion: The results of this study indicated that rodents trapped from the student's colleges in University Putra Malaysia are infected with various ectoparasites species that might play an important role in the transmission of certain zoonotic diseases to humans. Therefore, we conclude that there is potential risk of rodent-borne zoonotic diseases transmission to humans in the study area. Awareness of prevention and control of rodent-borne diseases should be introduced to educate the students on the importance of zoonotic diseases associated with rodents.

Keywords: Ectoparasites; rodents; zoonotic; diseases.

\section{INTRODUCTION}

Several numbers of devastating diseases in tropical and sub-tropical areas of the world are as the result of infection with parasites. A World Health Organization (WHO) report on the leading causes of death worldwide shows that one-third of all deaths are due to parasitic and infectious diseases [1]. Rodents play an important role as hosts for ectoparasites and reservoirs for various types of viruses, bacteria, rickettsia, protozoa and helminths which are responsible for causing zoonotic diseases to humans and other vertebrate animals [2]. However, these zoonotic diseases from rodents can be transmitted to humans indirectly through ectoparasites such as mites, ticks, and fleas. It can also be transmitted directly through bite wounds, consuming food or water contaminated with rodent feces or urine.

The etiological agents of many infectious diseases utilize invertebrate hosts during their life cycle. Most of these agents are adapted to hematophagous arthropods that share their vertebrate hosts. Therefore, the identification of these arthropod vectors and vertebrate reservoirs is usually a key to sustain an efficient control of vector-borne diseases.

Ectoparasites that include lice, fleas, mites, and ticks are commonly found in wild rats and other rodent species. They are classified into five main groups namely; Mesostigmata (mites), Acarina (ticks), Prostigmata (chiggers), Phthiraptera (lice) and Siphonaptera (fleas) [3]. Prevalence studies on ectoparasites infestation in rodent has been reported all over the world $[4,5,2,6,7,8,9,10$, $11,12,13]$. But due to ecological differences in different areas of the country, the parasitic fauna of the rodents in each ecological setting might be different. This notion justifies new studies on parasitic infection of the rodents in other areas of the country.

The present study aimed to determine the prevalence of ectoparasites species in rodents in relation to gender, age, and habitat of the host.

\section{MATERIALS AND METHODS}

\subsection{The Study Sites}

The study was conducted between September 2018 -March 2019 in University Putra Malaysia, which is located $\left(2^{\circ} 59^{\prime} 34.19^{\prime \prime} \mathrm{N}\right.$; $\left.101^{\circ} 42^{\prime} 16.79 " \mathrm{E}\right)$ in central Peninsular Malaysia, Kuala Lumpur. The University has seventeen student's residential colleges out of which four colleges were selected randomly for the study. The climate of the study area is tropical climate with, 
an annual average temperature of about 27degree Celsius. Typically receives minimum $2,600 \mathrm{~mm}$ (100 in) of rain annually; June and July are relatively dry, but even then, rainfall typically exceeds $133 \mathrm{~mm}$ (5.2 in) per month.

\subsection{Collection of Rodents}

The rodents were trapped using rectangular metal trap baited with meat, as previously described [14]. The traps were set in the late evening closer to garbage storage, students hostel and canteen areas in the University campus. The traps were brought back to the Parasitology laboratory of the Department of Medical Microbiology and Parasitology the following morning for investigation.

\subsection{Animal Euthanisation}

Trapped rodents were euthanised using carbon monoxide. The animals were placed into a sealed chamber, and carbon monoxide was introduced. After the successful euthanisation of the animal, the rodents were removed and place on a clean dissecting board for identification and dissection $[15,16,14]$. After the euthanisation, the rats were classified as adult or juveniles based on their weight, length, and the degree of development of their reproductive organs and their gender was also determined [14].

\subsection{Collection of Ectoparasites}

The fur of the animal was combed thoroughly on to a white A4 plan sheet paper using a fine-tooth comb. The Parasites that fell on the white paper from the fur were collected and transferred into a bijou bottle containing $70 \%$ alcohol for preservation. Separate containers were used for each animal. A forcep was also used to dislodge the ticks and mites that are difficult to be detached using the comb. The insects collected were preserved before identification [14].

\subsection{Mounting and Identification of Ectoparasites}

The preserved ectoparasites were washed using lactophenol and sorted based on their morphology. Preliminary identification of preserved ectoparasites was made under a dissecting microscope. The identification of the ectoparasites was carried out by mounting the parasites on slides with Hoyer's mounting media and observed under a microscope (Nikon eclipse 50í. Japan). The identification was performed by determining the diagnostic characteristics of the ectoparasites. However, the identification of the ectoparasites was based on morphological characteristics using taxonomic keys $[17,18]$. Identified ectoparasites specimens were classified into four groups, including fleas, mites, ticks, and lice.

\subsection{Statistical Analysis}

All analysis was carried out using graph prism statistical software and excels spreadsheet. Data were presented in percentage. Non-parametric test such as Mann Whitney and Kruskal Wallis test were used to compare the mean differences in parasitic infection between the gender, age, and habitat of the host. $P<0.05$ was considered Significance.

\section{RESULTS}

A total of 89 rodents that comprised of three different species ( $R$. norvegicus, $R$. tiomanicus, and $R$. r. diardii) were examined for ectoparasites. However, eight genera of ectoparasites consisting of seven species that belong to four different groups were identified in the present study. Three species of mites ( $L$. echidnina, L. nuttalli, O. bacoti), two species of ticks (I. granulatus, Heamaphysalis spp.), two species lice $(P$. spinoluso, $H$. pacifica), and one species of flea ( $X$. cheopis) were identified. Fig. 1 shows the prevalence of ectoparasites groups according to host specie. In $R$. norvegicus mites are found to be the most prevalent group with $67.86 \%$ prevalent rate, followed by lice and flea which have same prevalence rate of $42.86 \%$ respectively, the less prevalent group was tick (41.4\%). Ticks are the most encountered ectoparasites in R. r. diardii with $45.45 \%$ of $R$. $r$. diardii specie positive for ticks, followed by fleas $(34.9 \%)$, lice $(32.9 \%)$ and mites $(31.8 \%)$. Moreover, in $R$. tiomanicus, fleas $(6.71 \%)$ are found to the most prevalent ectoparasites followed by ticks $(52.94 \%)$, lice $(32.35 \%)$, and mites $(23.53 \%)$. The overall prevalence of infestation shows that $55 \%$ of the rodents captured were positive for at least one species of parasites.

The results in Table 1 show the prevalence and intensity of ectoparasites in relation to the habitat of rodents. All the rodents captured from the four habitats were found infested with similar ectoparasites species. However, rodent trapped from college 11 showed high ectoparasites infestation rate with $45.8 \%$ are positive for at 
least one species of ectoparasites, followed by college 10 with $41 \%$, college chancellor $38 \%$, and college 17 which has the less prevalence rate of $29.6 \%$. A Kruskal-Wallis $\mathrm{H}$ test showed that there was a statistically significant difference in the prevalence of ectoparasites infestation between rodents from the four colleges, $H=13.55, P=.0036$.

Table 2 shows the distribution of ectoparasites infestation in relation to the gender of the host. The results showed that more male rodents $45.8 \%$ were infested with ectoparasites compare to the female that has a prevalence rate of $30.8 \%$. Furthermore, Mann Whitney $U$ test indicated that the differences in terms of parasitic infection between male and female rodent were not statistically significant $(P>0.05 ; \quad P=.87)$. However, in Male rodents, the most prevalent species of ectoparasites species identified were $X$ cheopis $(64.5 \%), H$. pacifica $(55.5 \%)$, Haemaphysalis sp. (50\%), P. spinulosa (50\%). Whereas I. granulatus $(33.8 \%)$, L. nuttalli $(33.3 \%)$, L. echidnina $(27.7 \%)$, O. bacoti $(27.7 \%)$, were found to be less prevalent species. Meanwhile in female $X$. cheopis $(37.7 \%), P$. spinulosa $(35.8 \%)$, O. bacoti $(35.8 \%)$, and $H$. pacifica $(30.1 \%)$ showed the highest prevalent rate, whereas were $L$. echidnina $(24.1 \%), L$. nuttalli (26.4\%), and I. granulatus (28.3\%) Haemaphysalis sp. (28.3\%) shows a low infestation rate.

The rodents population was composed of more adult $(n=50 / 56)$ than juvenile $(n=39 / 44)$. However, both the adult and juvenile wild rats were found positive for ectoparasites parasites. The results show that ectoparasitic infestation was slightly higher among the adult rodents with $42.9 \%$ of the adult are infested with at least one species of ectoparasites whereas $32.2 \%$ of the male rodent was also found infested with at least one species of ectoparasites, But however the difference was not statistically significant $(P=.91$, $U=30.50$, Mean rank for adult $=66.50$, Mean rank for juvenile $=6950$ ) (Table 3). Among the adult, high infestation rate with Xenopsylla cheopis (79.9\%), Polyplax spinulosa (48.7\%), Haemaphysalis sp. (46.1\%), was observed compared to $L$. nuttalli $(38.4 \%), L$. echidnina $(30.7 \%)$, O. bacoti $(38.4 \%)$, I. granulatus (33.3\%), H. pacifica (30.7\%). Whereas in juvenile $H$. pacifica $48 \%, \quad P$. spinulosa $36 \%$, Haemaphysalis sp. 36\%, L. echidnina (32\%), I. granulatus $(32 \%), X$. cheopis $(30 \%)$, were the most encountered ectoparasites among the juvenile rodents compared to $L$. nuttalli $(22 \%), O$. bacoti $(28 \%)$ which are rarely observed.

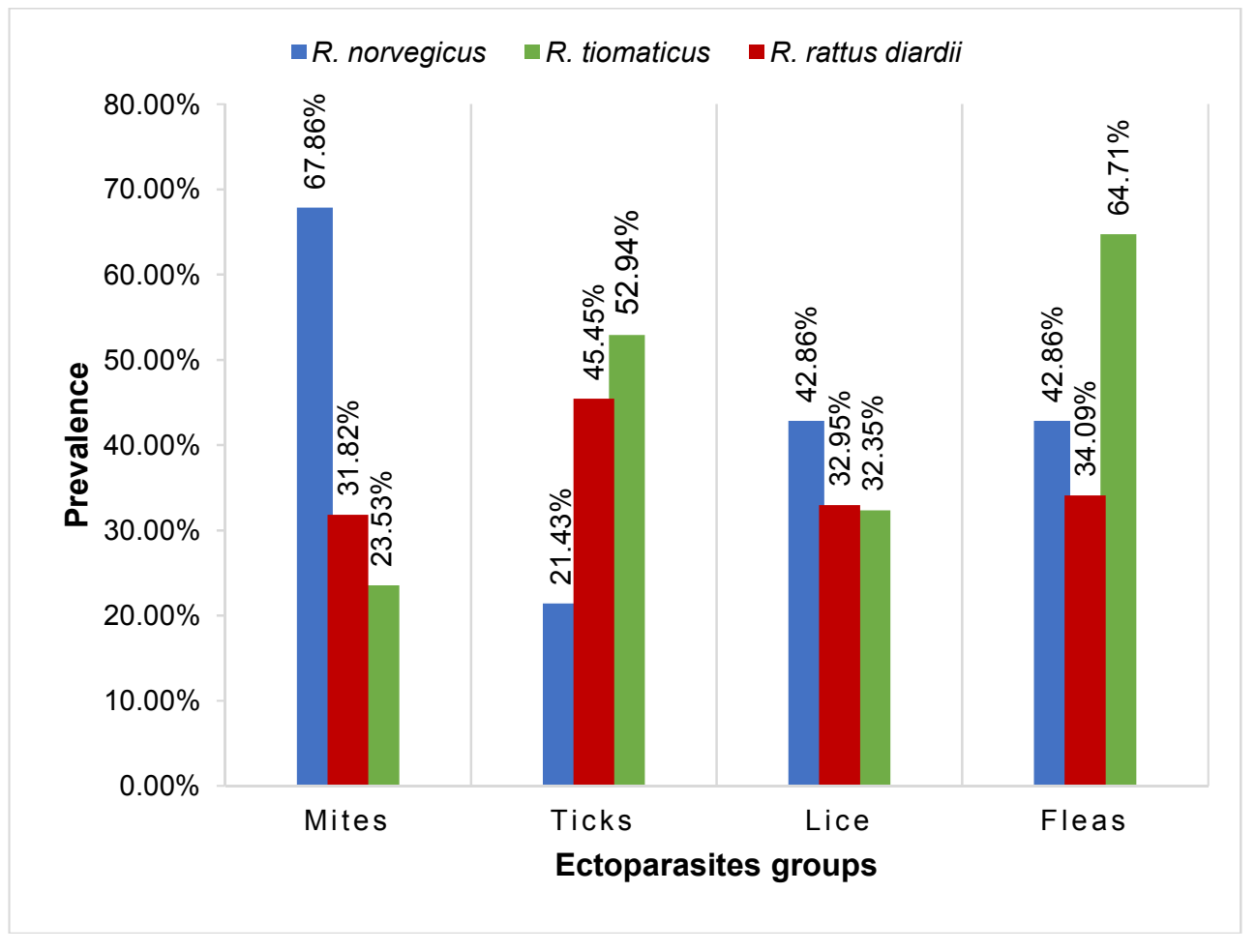

Fig. 1. Prevalence of ectoparasites on rodents according species of rodents 
Mustapha et al.; ARRB, 32(1): 1-10, 2019; Article no.ARRB.49523

Table 1. Prevalence and intensity (Mean \pm SEM) of ectoparasites infection among rodents trapped from student's hostel

\begin{tabular}{|c|c|c|c|c|c|c|c|c|}
\hline \multirow{3}{*}{$\begin{array}{l}\text { Habitat } \\
\text { No. examined }\end{array}$} & \multirow{2}{*}{\multicolumn{2}{|c|}{$\begin{array}{c}\text { College } 17 \\
(n=32)\end{array}$}} & \multirow{2}{*}{\multicolumn{2}{|c|}{$\begin{array}{c}\text { College Chancellor } \\
(n=19)\end{array}$}} & \multirow{2}{*}{\multicolumn{2}{|c|}{$\begin{array}{c}\text { College } 10 \\
(n=18)\end{array}$}} & \multirow{2}{*}{\multicolumn{2}{|c|}{$\begin{array}{c}\text { College 11 } \\
(n=21)\end{array}$}} \\
\hline & & & & & & & & \\
\hline & $\mathbf{P} \%$ & $\mathrm{X} \pm \mathrm{SE}$ & $\mathbf{P} \%$ & $\mathrm{X} \pm \mathrm{SE}$ & $\mathbf{P} \%$ & $\mathrm{X} \pm \mathrm{SE}$ & $\mathbf{P} \%$ & $\mathrm{X} \pm \mathrm{SE}$ \\
\hline L. nuttalli & $9(28.1 \%)$ & $1.33 \pm 0.35$ & $3(15.7 \%)$ & $3.00 \pm 0.35$ & $7(33.3 \%)$ & $1.43 \pm 0.41$ & $7(38 \%)$ & $2.57 \pm 0.71$ \\
\hline L. echidnina & $9(28.1 \%)$ & $1.22 \pm 0.74$ & $9(47.3 \%)$ & $1.67 \pm 0.35$ & $8(38 \%)$ & $1.75 \pm 0.54$ & $2(11.1 \%)$ & $4.00 \pm 0.20$ \\
\hline O. bacoti & $8(25 \%)$ & $1.50 \pm 0.35$ & $5(26.3)$ & $1.80 \pm 0.35$ & $5(23.8 \%)$ & $1.80 \pm 0.35$ & $11(61.1 \%)$ & $1.00 \pm 0.54$ \\
\hline I. granulatus & $7(21.8 \%)$ & $1.29 \pm 0.35$ & $6(31.5 \%)$ & $1.83 \pm 0.54$ & $11(52.3 \%)$ & $0.91 \pm 0.54$ & $11(61.1 \%)$ & $1.18 \pm 0.74$ \\
\hline Haemaphysalis sp. & $13(40.6 \%)$ & $1.23 \pm 0.74$ & $7(36.8 \%)$ & $1.29 \pm 0.35$ & $9(42.8 \%)$ & $1.56 \pm 0.41$ & $4(22.2 \%)$ & $1.50 \pm 0.35$ \\
\hline P. spinulosa & $12(37.5 \%)$ & $1.17 \pm 0.54$ & 7 (36.8\%) & $1.14 \pm 0.20$ & $8(38 \%)$ & $1.13 \pm 0.35$ & $10(55.5 \%)$ & $1.20 \pm 0.35$ \\
\hline H. pacifica & $7(21.8 \%)$ & $1.29 \pm 0.35$ & $10(52.6 \%)$ & $1.40 \pm 0.74$ & $9(42.8 \%)$ & $1.56 \pm 0.54$ & $10(55.5 \%)$ & $0.80 \pm 0.41$ \\
\hline X. cheopis & $11(34.3 \%)$ & $1.27 \pm 0.74$ & $11(57.8 \%)$ & $1.18 \pm 0.20$ & $12(57.1 \%)$ & $1.50 \pm 0.35$ & $11(61.1 \%)$ & $1.09 \pm 0.35$ \\
\hline O. P & $76(29.6 \%)$ & & $58(38 \%)$ & & $69(41 \%)$ & & $66(45.8 \%)$ & \\
\hline
\end{tabular}

${ }^{*}$ Prevalence $(P \%)=$ No. of rats infested / Total no. of rats examined multiply by 100, Intensity (mean abundance = Mean no. of ectoparasites collected / Total no. of host infested

Table 2. Distribution of the ectoparasites infection according to the gender and species of the host

\begin{tabular}{|c|c|c|c|c|c|c|c|c|}
\hline \multirow[t]{2}{*}{ Ectoparasite species } & \multicolumn{4}{|c|}{ Male $(n=36)$} & \multicolumn{4}{|c|}{ Female $(n=53)$} \\
\hline & RR & RN & RT & Total & RR & RN & RT & Total \\
\hline L. nuttalli & $5(13.8 \%)$ & $4(11.1 \%)$ & $3(8.3 \%)$ & $12(33.3 \%)$ & $6(11.3 \%)$ & $5(9.43 \%)$ & $2(3.77 \%)$ & $14(22 \%)$ \\
\hline L. echidnina & $8(22.3 \%)$ & $3(8.33 \%)$ & $4(11.1 \%)$ & $15(41.6 \%)$ & $4(7.54 \%)$ & $7(13.2 \%)$ & $1(1.88 \%)$ & $13(32 \%)$ \\
\hline $\begin{array}{l}\text { O. bacoti } \\
\text { Ticks }\end{array}$ & $4(11.1 \%)$ & $4(11.1 \%)$ & $2(5.5 \%)$ & $10(27.7 \%)$ & $10(18.8 \%)$ & $7(13.2 \%)$ & $2(3.77 \%)$ & $19(28 \%)$ \\
\hline I. granulatus & $6(16.6 \%)$ & $4(11.1 \%)$ & $4(11.1 \%)$ & $14(38.8 \%)$ & $7(13.2 \%)$ & $5(9.43 \%)$ & $3(5.66 \%)$ & $15(32 \%)$ \\
\hline $\begin{array}{l}\text { Haemaphysalis sp. } \\
\text { Lice }\end{array}$ & $10(27.7 \%)$ & $6(16.6 \%)$ & $2(5.5 \%)$ & $18(50 \%)$ & $8(15.0 \%)$ & $5(9.43 \%)$ & $2(3.77 \%)$ & $15(36 \%)$ \\
\hline P. spinulosa & $9(25.0 \%)$ & $5(13.8 \%)$ & $4(11.1 \%)$ & $18(50 \%)$ & $7(13.2 \%)$ & $7(13.2 \%)$ & $5(9.43 \%)$ & $19(36 \%)$ \\
\hline $\begin{array}{l}\text { H. pacifica } \\
\text { Flea }\end{array}$ & $8(22.3 \%)$ & $10(27.7 \%)$ & $2(5.5 \%)$ & $20(55.5 \%)$ & $7(13.2 \%)$ & $5(9.43 \%)$ & $4(7.54 \%)$ & $16(48 \%)$ \\
\hline $\begin{array}{l}\text { X. cheopis } \\
\text { O.P }\end{array}$ & $12(33.3 \%)$ & $9(25.0 \%)$ & $4(11.1 \%)$ & $\begin{array}{l}25(69.4 \%) \\
45.8 \%\end{array}$ & $9(16.9 \%)$ & $7(13.2 \%)$ & $4(7.54 \%)$ & $\begin{array}{c}20(30 \%) \\
30.8 \%\end{array}$ \\
\hline
\end{tabular}

${ }^{*} R R=$ R.r. diardii, $R N=R$. norvegicus, $R T=$ Rattus tiomanicus, $O . P=$ Overall prevalence 
Table 3. Distribution of the ectoparasites infection according age of the host

\begin{tabular}{lll}
\hline Ectoparasite species & Adult (n=50) & Juvenile (n=39) \\
\hline Mites & & \\
L. nuttalli & $15(38.4 \%)$ & $11(22 \%)$ \\
L. echidnina & $12(30.7 \%)$ & $16(32 \%)$ \\
O. bacoti & $15(38.4 \%)$ & $14(28 \%)$ \\
\hline Ticks & $13(33.3 \%)$ & $16(32 \%)$ \\
I. granulatus & $18(46.1 \%)$ & $15(36 \%)$ \\
Haemaphysalis sp. & $19(48.7 \%)$ & $18(36 \%)$ \\
\hline Lice & $12(30.7 \%)$ & $24(48 \%)$ \\
$P$. spinulosa & \multicolumn{2}{|c}{} \\
H. pacifica & $30(79.9 \%)$ & $15(30 \%)$ \\
Flea & $42.9 \%$ & $32.2 \%$ \\
X. cheopis & & \\
\hline
\end{tabular}

\section{DISCUSSION}

The ectoparasites of rodents play an important role as vectors of pathogenic microorganisms that transmit different diseases to humans $[19,20]$. However, several studies on ectoparasites of rodents were reported in Malaysia [21,22,23], and other neighboring countries, including Indonesia, Viet $\mathrm{Nam}$, Bangladesh, and Singapore [7]. Fleas are known to transmit bubonic plague, essentially a zoonotic disease caused by a bacteria Yersinia pestis, from rodents to humans. However, in South and Southeast Asia, plague remains endemic in several regions (e.g., India and Viet Nam), with regular outbreaks among humans [7]. The flea species $X$. cheopis and $C$. canis serve as intermediate hosts for species of tapeworms that occasionally infect humans [24].

Furthermore, it has been reported that fleas serve as vectors of several diseases that include Salmonellosis, Tularemia, Leishmaniasis, Trypanosomiasis and relapsing fever infections. In the current study, we recorded the presence of $X$. cheopis among wild rat captured at the prevalence rate of $84.4 \%$. However, the high prevalence of $X$. cheopis in the present study indicates a potential risk of transmission of diseases (Rickettsia typhi and plague,) associated with this parasite to humans. Other previous studies have reported a high prevalence of $X$. cheopis in rodents $[21,22,13,25]$. According to $\mathrm{WHO}$ in 2015, the $X$. cheopis on wild rats represents a potentially dangerous situation with regard to increased plague risk for human beings in the event of an outbreak of plague (WHO Plague Manual). Although, there have not been outbreaks in recent years in Peninsular Malaysia. But, It's endemic in other Southeast Asian countries, including Indonesia [26,27]. Thailand [28], Vietnam [29] and Myanmar [30]. The first case of plague in Malaysia occurred in Penang in 1896 , and the most recent case was in Perak in 1928 [31]. The mite species $L$. nuttali, $L$. echidinus and $O$. bacoti are also ectoparasites that are often found in rodents. However, in the present study, all three species of mites were found in the trapped rodents. The $L$. nuttali, $L$. echidnina and $O$. bacoti are medically importance ectoparasites species, and they are known to transmit diseases to humans. The mite species $O$. bacoti does not only parasitizes the wild and domestic rats but also bites the human as the accidental host, consequently leading to transmission of filariasis to humans since that the $O$. bacoti is the intermediate host of the filarial worm [8].

Furthermore, $O$. bacoti also caused mite dermatitis in humans. The first case report of $O$. bacoti causing dermatitis in humans was reported from Australia, followed by other cases reported in the USA and Germany [32]. It has been estimated that approximately $80 \%$ of the wild rodents in Germany are infested by this parasite [32]. In Malaysia, the first authentic case of dermatitis caused by $O$. bacoti was reported in 1974 [33]. Therefore, the presence of $L$. nuttali, L. echidnina, $O$. bacoti in the rodent's population in the student's residential colleges in UPM may have a potential risk to students living in the respective colleges.

Two species of ticks recovered in the present study include; Haemaphysalis sp., and $I$. granulatus. The Haemaphysalis sp. is medical importance tick species which transmits different groups of pathogens including protozoa (Babesia), bacteria (Tularemia), Richettsia sp. 
and arboviruses. Their bites can also cause stress and blood loss to the animal and human hosts [34]. I. granulatus is also one of the medical importance ectoparasites because it is the main vector of Langat Virus [35]. Apart from Langat virus, Ixodes sp. is also known to transmit other pathogens such as babesiosis, human granulocytic anaplasmosis, Lyme disease [17]. In Malaysia, Ixodes sp. is involved in the spread of tick typhus and $Q$ fever to humans in the climax forest of Peninsular Malaysia [36]. The high prevalence of tick species $(77.7 \%)$ infesting rodents seen in the present study may be due to the suitable environment for tick survival, because ticks are likely to be found in habitats such as shrubs, forest, and plantation and some of the students hostels in UPM where the trapping of rodents conducted was very close to forest plantations. Previous similar studies have also reported these tick species infesting wild rats and other forest rodents $[37,2,38,39]$.

The $P$. spinulosa and $H$. pacifica were two common lice species encountered in the present study. They were found infecting rodent population at the prevalence rate of $37 \%$, and $36 \%$ respectively. Lice are medically importance ectoparasites in both human and rodents; they are known to harbor and transmit plague bacilli and transmit tularemia bartonellosis to humans. There bites in human causes a condition called pediculosis. Furthermore, $P$. spinulosa can also transmit T. lewisi, Hemobartonella muris, and Rickettsia typhi and the clinical manifestation associated with Polyplax sp. comprised of anaemia and general unthriftiness, leading to debilitation [37]. In Malaysia, infestation with Polypolax sp and $H$. pacifica has been previously reported in urban rats $[3,22]$. $H$. pescinata, $P$. spinulosa and $H$. pacifica have also been previously reported in rodents from Kuala Selangor Nature Park [37]. Similar findings on rodents ectoparasites infestation with louse species $P$. spinulosa and $H$. pacifica has been reported worldwide $[12,6,40,9]$.

Age-related differences in term of ectoparasitic infestations among the wild rats observed in the present study could be attributed to the fact that older or adults rats have a longer exposure time to potential infection compared to juvenile [41]. On the other hand, the low prevalence of infestation observed in the juvenile rats is probably biased due to the low number of juvenile rats captured in the present study. Other finding with similar observations for host age differences in infestation were also reported [3].
More male $(45.8 \%)$ rats were infested with ectoparasites despites there low number compare to the female which has a prevalence rate of $30.8 \%$. However, this finding may be as a results of wider home range of male rats that tend to overlap (in search for food, reproductive partner, courtship) which increases their exposure to ectoparasitic infections, whereas the reproductive female shows a stronger sitespecific organization which could explain the low rate of transmission $[42,43]$. Other previous studies have reported a similar finding $[42,44]$. The similarities in species recovered from four different locations may be as a result of similarity in the geographical structure of the samplings sites since the trapping was carried out within similar geographical areas that have similar vegetation cover. It has been previously reported similarity in geographical structure can bring the similarity in the fauna of the ectoparasites in the different regions [44].

\section{CONCLUSION}

The finding of this study showed that wild rats captured from four colleges (College 17, College Chancellor, College 10 and 11) in UPM are infected with different ectoparasites of zoonotic importance. This suggests a potential risk of arbo-borne disease transmission to humans. Therefore, there is a need to promote awareness on prevention and control of rodent-borne diseases to educate the students on the importance of zoonotic diseases associated with rodents. Moreover, further studies should focus on the distribution of diseases which are transmitted by ectoparasites to humans not only in UPM campus but also in places, where most of the population live in close contact to rodents, livestock, and dogs.

\section{ETHICAL APPROVAL}

All authors hereby declare that Principles of laboratory animal care (NIH publication No. 8523 , revised 1985) were followed, as well as with guidelines of the animal care and use committee (ACUC), University Putra Malaysia. All experiments have been examined and approved by the Animal ethics committee of the University of Putra Malaysia (Ref. No: UPM/IACUC/AUPR039/2018).

\section{ACKNOWLEDGEMENTS}

The authors acknowledge the financial support of University Putra Malaysia. 


\section{COMPETING INTERESTS}

Authors have declared that no competing interests exist.

\section{REFERENCES}

1. World Health Organization Report (WHO). 50 Facts: Global health situation and trends. 1955-2025. World Health Report; 2018.

(Accessed 3 September 2018)

Available:https://www.who.int/whr/1998/me dia_centre/50facts/en/

2. Gholamhossein M, Hamidi K, Nourani L. Occurrence of ectoparasitic arthropods (Siphonaptera, Acarina, and Anoplura) on rodents of Khorasan Razavi Province, Northeast of Iran. Asian Pacific Journal of Tropical Disease. 2015;18(8):7-12.

3. Paramasvaran $S$, Sani RA, Hassan L, Krishnasamy M, Jeffery $J$, Oothuman $P$, et al. Ectoparasite fauna of rodents and shrews from four habitats in Kuala Lumpur and the states of Selangor and Negeri Sembilan, Malaysia and its public health significance. Tropical Biomedicine. 2009; 26(3):303-311.

4. Kohls GM. Malaysian Parasites-XVIII. Ticks (Ixodoidea) of Borneo and Malaya. Studies from the Institute for Medical Research, Federated Malay States. 1957;28.

5. Sumangali RP, Rajapakse RS. Ecto and Endo parasites of rodents from two selected sites in Kandy district. Ceylon Journal of Science. 2012;41(1):71-77.

6. Yang $\mathrm{P}$, Oshiro $\mathrm{S}$, Warashina, W. Ectoparasitic Arthropods occurring on Rattus norvegicus and Rattus rattus collected from two properties on the Island of Oahu, Hawaii (Acarina, Siphonaptera, and Anoplura). Proceeding of Hawaiian Entomological Society. 2009;41:53-56.

7. Fuehrer HP, Igel $P$, Treiber $M$, Baumann TA, Riedl J, Swoboda P, Noedl $H$. Ectoparasites of livestock, dogs, and wild rodents in the Chittagong hill tracts in Southeastern Bangladesh. Parasitology Research. 2012;111(4):1867-1870.

8. Rahdar M, Vazirianzadeh B. Identification of collected ectoparasites of rodents in the west of Khuzestan Province (Ahvaz and Hovizeh), Southwest of Iran. Asian Pacific Journal of Tropical Disease. 2015;1808(4):1-6.
9. Harrison A, Robb GN, Alagaili AN, Hastriter MW, Apanaskevich DA, Ueckermann EA, et al. Ectoparasite fauna of rodents collected from two wildlife research centres in Saudi Arabia with discussion on the implications for disease transmission. Acta Tropica. 2015;147(3):15.

10. Okorafor KA, Odaibo AB, Eleng I, Okete JA. Occurrence and prevalence of ecto and gastrointestinal parasites in Wild cane Rats (Tryonomys swinderianus) from Oyo State, South-Western Nigeria. European Journal of Zoological Research. 2012;1(3): 70-76.

11. Stanko M, Miklisova D, De Bellocq JG, Morand S. Mammal density and patterns of ectoparasite species richness and abundance. Oecologia. 2002;131(2):289295.

12. Frye MJ, Firth C, Bhat M, Firth M, Che X, Lee D, Williams SH. Preliminary survey of ectoparasites and associated pathogens from Norway rats in New York City. Journal of Medical Entomology. 2015; 52(2):253-259.

13. Fagir DM, El-Rayah EA. Parasites of the Nile rat in rural and urban regions of Sudan. Integrative Zoology. 2009;4(2):179187.

14. Herbreteau V, Jittapalapong S, Rerkamnuaychoke W, Chaval Y, Cosson JF, Morand S, Editors. Protocols for field and laboratory rodent studies. $2^{\text {nd }} \mathrm{Ed}$. Kasetsart University Press; 2011.

15. Lim Boo Liat. The house rodents and house shrew in Malaysia and Southeast Asia. Utar Agriculture Science Journal. 2015;1(4):43-50.

16. Leary S, Underwood W, Anthony R, Cartner S. Guidelines for the euthanasia of animals: $2^{\text {nd }}$ Ed. American Veterinary Medical Association; 2013.

17. Mathison BA, Pritt S. Laboratory identification of arthropod ectoparasites. Clinical Microbiology Reviews. 2014;27(1): 48-67.

18. Anne M. Zajac, Gary A. Conboy. Veterinary clinical parasitology. $8^{\text {th }}$ Ed. UK: Wiley Blackwell; 2012.

19. Kourosh A, Mitra S, Iraj M, Amir A, Hamid $H$, Mohammad $A$, et al. Intestinal helminths in different species of rodents in North Khorasan Province, Northeast of Iran. Iranian Journal of Parasitology. 2017;12(2):267-273. 
20. Meerburg BG, Singleton GR, Kijlstra A. Rodent-borne diseases and their risks for public health. Critical Reviews in Microbiology. 2009;35(3):221-270.

21. Madinah A, Fatimah A, Mariana A, Abdullah MT. Ectoparasites of small mammals in four localities of wildlife reserves in Peninsular Malaysia. Southeast Asian Journal of Tropical Medicine and Public Health. 2011;42(4): 803-813.

22. Nursheena $S$, Mohd-Zain SN, Arnez $S$, Khalil S, Braima KA, Abdulaziz NM, et al. Ectoparasites of murids in Peninsular Malaysia and their associated diseases. Parasites and Vectors. 2015;8(2):1-10.

23. Premaalatha $B$, Nurulaini $R$, Zawida $Z$, Norakmar I, Zaini CM, Ramlan M. A survey of bacterial and parasitic infections of rats caught in the veterinary research institute, Ipoh. Malaysian Journal of Veterinary Research. 2010;6(7):45-50.

24. United State Department of Health, Education, and Welfare Public Health Service Communicable Disease Center. Fleas of public health importance and their control. Public Health Service Publication. 1962;772(5):1-10.

25. Ogunniyi $T$, Balogun $H$, Shasanya $B$. Ectoparasites and endoparasites of peridomestic house-rats in Ile-Ife, Nigeria and implication on human health. Iranian Journal of Parasitology. 2014;9(1):134140.

26. Hadi TR, Sarbini SD. Survey of small mammal ectoparasites in West Sumatra, Indonesia. Southeast Asian Journal of Tropical Medicine and Public Health. 1981;12(2):7-27.

27. Turner RW, Martoprawiro S. Dynamics of the plague transmission cycle in central Java (ecology of potential flea vectors). Health Studies in Indonesia. 1974;11(2).

28. Elbel RE, Thaineua MA. Flea and rodent control program for plague prevention in Thailand. The American Journal of Tropical Medicine and Hygiene. 1957;6(2): 280-293.

29. Olson WP. Rat-flea indices, rainfall, and plague outbreaks in Vietnam, with emphasis on the Pleiku area. The American Journal of Tropical Medicine and Hygiene. 1969;18(4):621-628.

30. Brooks JE. Plague in small mammals and humans in Rangoon, Burma. Southeast
Asian Journal of Tropical Medicine and Public Health. 1977;8(3):335-344.

31. Milne JC. A brief review of fifty years of medical history in Selangor, Federation of Malaya. Medical Journal of Malaya. 1948;2(3):161-173.

32. Beck W, Folster-holst R. Tropical rat mites (Ornithonyssus bacoti) serious ectoparasites. Journal of German Society of Dermatology. 2009;7:667-670.

33. Nadchatram M, Ramalingam S. Dermatitis caused by Ornithonyssus bacoti. Southeast Asian Journal of Tropical Medicine and Public Health. 1974;5(1):15.

34. Louis AM. Global importance of ticks and associated infectious disease agents. Clinical Microbiology Newsletter. 2009; 31(5):33-36.

35. Smith CE. A virus resembling Russian spring-summer encephalitis virus from an ixodid tick in Malaya. Nature. 1956;4:581582.

36. Marchette. Rickettsioses (tick typhus, qfever, urban typhus) in Malaya. Journal of Medical Entomology. 1966;2(4):339-371.

37. Chuluun B, Mariana A, Ho T, Mohd K. A preliminary survey of ectoparasites of small mammals in Kuala Selangor Nature Park. Tropical Biomedicine. 2005;22(2): 243-247.

38. Kim CM, Yi YH, Yu DH, Lee MJ, Cho MR, Desai AR, Chae JS. Tick-borne rickettsial pathogens in ticks and small mammals in Korea. Applied and Environmental Microbiology. 2006;72(9):5766-5776.

39. Mariana Z, Zuraidawati TM, Mohd KI, Saleh MS. A survey of ectoparasites in Gunung Stong forest reserve, Kelantan, Malaysia. Southeast Asian Journal of Tropical Medicine and Public Health. 2005;36(5):1125-1131.

40. Shahi M, Pakari A. A study on rodent ectoparasites in Bandar Abbas: The main economic southern seaport of Iran. Iranian Journal of Environmental Health Science \& Engineering. 2007;4(1):173-176.

41. Easterbrook JD, Kaplan JB, Glass GE, Watson J, Klein SL. A survey of rodentborne pathogens carried by wild-caught Norway rats: A potential threat to laboratory rodent colonies. Laboratory Animals. 2007;42(1):92-98.

42. Kowalski K, Bogdziewicz M. Sex differences in flea infections among rodent 
hosts: Is there a male bias? Parasitol Res. 2015;114(9):337-341.

43. David E, John T, Emlem JR. Studies on home range of brown rats. Journal of Mammalogy. 1948;29(4):207-225.
44. Krasnov BR, Stanko $M$, Matthee $S$, Laudisoit A, Leirs H, Khokhlova IS, Serge V. Male hosts drive infracommunity structure of ectoparasites. Oecologia. 2011;166:1099-1110.

(c) 2019 Mustapha et al.; This is an Open Access article distributed under the terms of the Creative Commons Attribution License (http://creativecommons.org/licenses/by/4.0), which permits unrestricted use, distribution, and reproduction in any medium, provided the original work is properly cited.

Peer-review history:

The peer review history for this paper can be accessed here: http://www.sdiarticle3.com/review-history/49523 